\title{
INCREASING THROUGHPUT IN AN AUTOMATED PACKAGING LINE WITH IRREDUCIBLE COMPLEXITY
}

\author{
Charles Harrell \\ Seth Winsor \\ Greg Teichert \\ Brigham Young University \\ 265 CTB \\ Provo, UT, 84602, USA
}

\begin{abstract}
Avery Dennison, a leading supplier of pressure-sensitive labeling material, was faced with the challenge of finding the most cost-effective way of increasing the theoretical throughput capacity of their Pesmel ${ }^{\circledR}$ automated packaging system by $20 \%$. Unfortunately, everyone had different ideas about what the best method would be for effecting the increase, but no one could substantiate their claims. Simulation removed the guesswork from the decision-making process ensuring that the improvements made would yield the desired results.
\end{abstract}

\section{INTRODUCTION}

Avery Dennison is a leading provider of pressure-sensitive labeling paper. Their plant in Greenfield, Indiana produces a variety of large rolls of this paper that are shipped to a number of different customers. The rolls range from 20 to 40 inches in diameter and from 50 to 1500 pounds and must be properly palletized, wrapped and secured before being shipped. This is the function of the Pesmel ${ }^{\circledR}$ automated packaging system. Rolls entering the system are bar coded, oriented, axially wrapped, palletized, stabilized and then entirely stretch wrapped to secure and protect the load. Rolls are oriented on the pallet in either an upright "pancake" position (Figure 1) or sideways in a "cradle" position (Figure 2). Forty percent of the rolls are pancake stacked and sixty percent are cradle packed. Pancake stacked rolls can have anywhere from one to four rolls on a pallet, while only one roll is cradle packed on a pallet. Once ready for shipping, these palletized rolls accumulate on a conveyor to await pickup by a forklift at which time they are taken to a staging area for shipping. Currently, the Pesmel is operating at maximum capacity and, barring interruptions, produces an average of 26.2 pallets $/ \mathrm{hr}$. In anticipation of a $20 \%$ increase in demand, Avery Dennison engineers were faced with the challenge of determining the most cost-effective way to increase throughput by $20 \%$.

This was a good candidate for the application of Theory of Constraint methodology (Goldratt 1993). Simulation has been shown in the past to be an effective tool for implementing Theory of Constraints (Zottolo et al. 2009), especially when attempting to find the most cost-effective way to elevate the constraint (Rippenhagen et al. 1998; Aybar, Potti, and LeBaron 2002). The first recommended improvements to the system, therefore, involved ways to exploit the bottleneck, which means never allowing it to be starved, blocked or interrupted. To prevent starving of the Pesmel system, it was recommended that a roll always be ready for processing. This means that the fetching cart must have a cycle time less than the Pesmel cycle time, and another roll must always be ready for pickup when a roll is deposited by the fetching cart. To prevent blockage, two recommendations were made: (1) keep a forktruck operator nearby to 
offload full pallet loads, and (2) provide additional buffering at output area to prevent blockage of the Pesmel. To prevent interruptions, it was recommended that equipment failures be reduced to a minimum and that operators are always available when needed. Management readily accepted these recommendations, so that the only remaining task was to provide a suitable recommendation for elevating the Pesmel capacity by $20 \%$.

To identify the weakest links in the Pesmel system and test whether and how much different solutions improve performance, a simulation of the Pesmel system was created using the ProModel ${ }^{\circledR}$ simulation software (Harrell, Ghosh, and Bowden 2004). The data needed to create an accurate simulation was gathered through in-depth time studies that were taken during a site visit, through analysis of videos of the system and also by requesting follow-up information from the Greenfield point of contact. The simulation was then verified by comparing its results to videos of known throughput. Once the base simulation had been verified, it was modified to simulate various options for improvement. By comparing the theoretical throughput resulting from the modifications, an accurate ranking of the concepts was achieved.

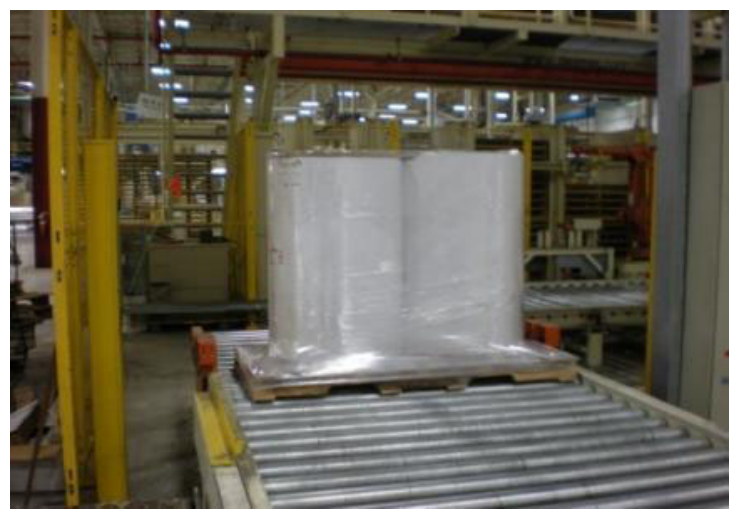

Figure 1: Pancake Packed Rolls

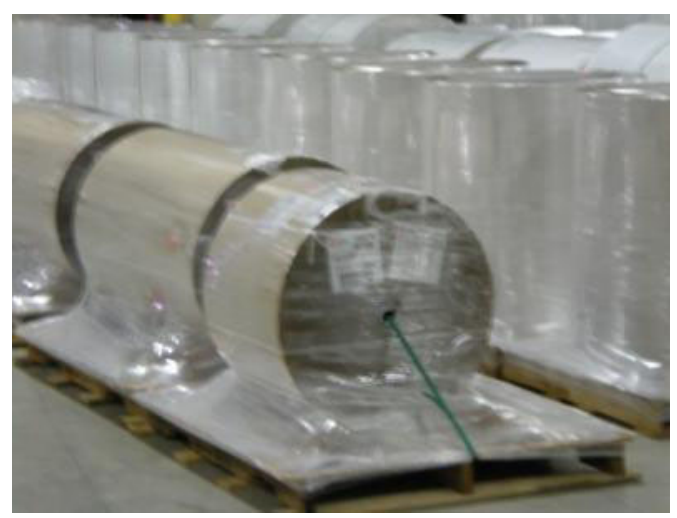

Figure 2: Cradle Packed Rolls

\section{DESCRIPTION OF OPERATION}

A schematic of the Pesmel system is shown in Figure 3. The system consists of several stations and several shuttle carts and conveyors for moving rolls and palletized loads from station to station. To begin with, a fetching cart (301) retrieves rolls (one at a time) from an upstream slitting operation and, if there is room, deposits it on the turntable. The turntable rotates 90 degrees and tilts to transfer the roll to the holding station (403). The roll waits at the holding station until cart 407 comes and moves it to the operator station (404) where labels are placed on the roll and data is entered on the computer.

After completing this manual operation, cart 407 moves the roll to the axial wrapper (405) where, if specified, the roll gets wrapped. Once wrapped the roll is transferred from the axial wrapping station to either the cradle pack table or the up-ender by cart 408. A request is also made at this point to send a pallet to the palletizing station so it is there when the roll arrives.

If the roll is to be cradle-packed, it is deposited at the cradle pack table where it waits for the manipulator arms to roll it onto the table. The roll waits on the table until cart 513 arrives with the specified pallet and pad and then is rolled by the manipulator arms onto the pallet to wait again for operator manual operations. Once the operator has labeled the roll and placed corrugated wedges on the pallet to stabilize the roll, the system is again set to resume processing of the roll. From here, cart 513 takes the cradlepacked roll to the pallet wrapper line and transfers it to that conveyor.

If the roll is to be pancake-stacked, it is taken from the axial wrapper (405) by Cart 408 and is deposited at the up-ender (502) where it is rotated 90 degrees so as to be on end. From here, it is transferred to the roll cart (503) which in turn transfers the roll via conveyor to the pusher/palletizer (506). 
Here the roll is pushed onto the pallet at the same rate as the pallet is fed out from underneath the palletizer shelf until the pallet and roll are successfully combined. If the roll is to be combined with other rolls on the same pallet, the first roll will wait for each subsequent roll to be added to the pallet one at a time. Once the roll(s) and pallet are combined, the chains that were feeding the pallet lower the unit onto the transfer conveyor (510) and are moved onto cart 513.

Cart 513 takes both pancake-packed rolls and cradle-packed rolls to the pallet-wrap conveyor. The unit is then transferred to the pallet wrapper line where it is securely stretch wrapped at station 604. From the wrapper, the unit continues down the line until it reaches the pivot table (610), where it is rotated 90 degrees and then transferred to the take-off line. There it awaits a forklift operator to be removed.

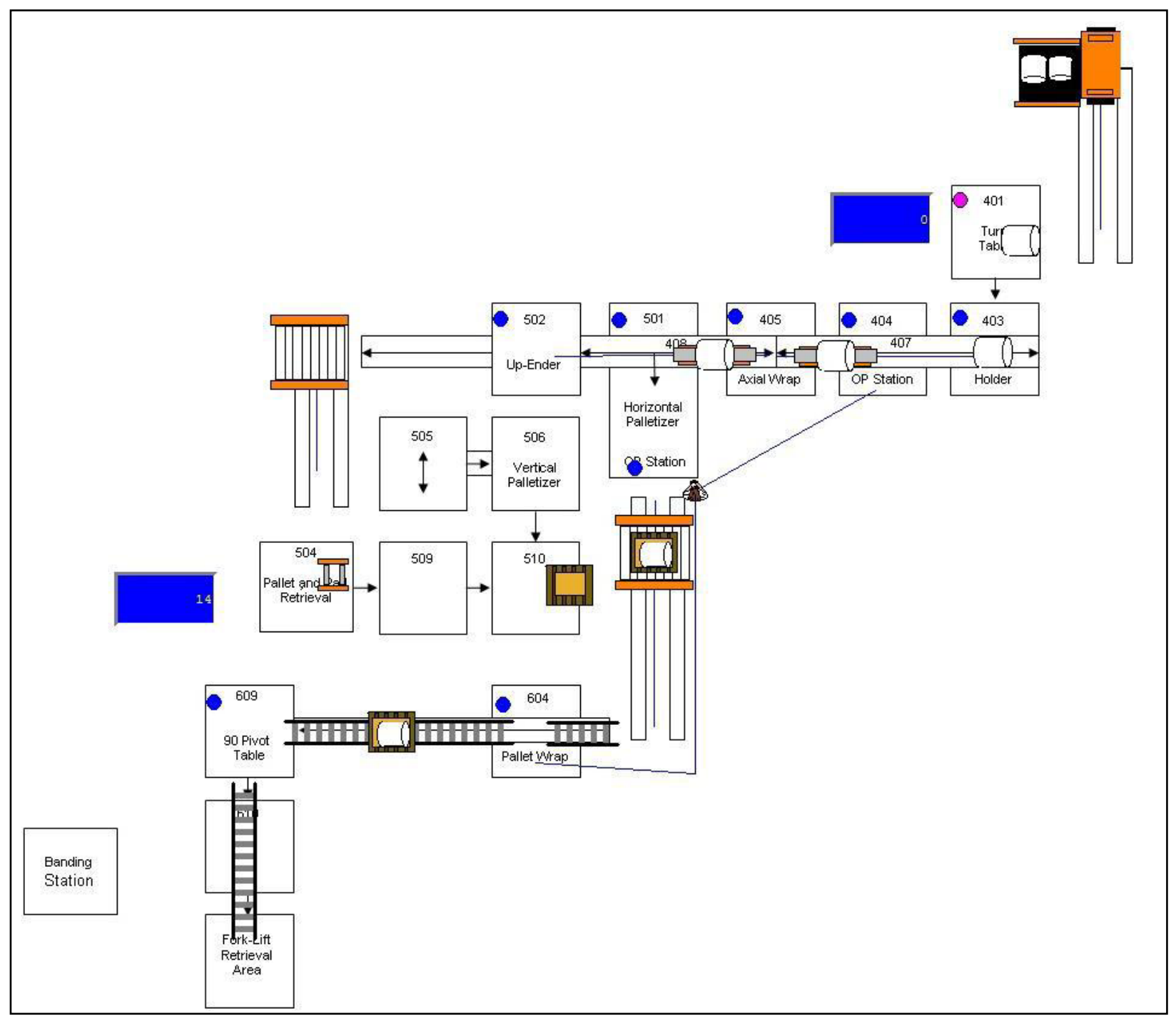

Figure 3: Simulation Screenshot of the Current Pesmel® System

\section{MODELING ASSUMPTIONS}

In order to test the effectiveness of the concepts in increasing throughput, ProModel ${ }^{\circledR}$ simulation software was used to create a computer model of the current Pesmel ${ }^{\circledR}$ packaging system. This allowed the 
simulation to be adapted to include the new concepts, so that the resulting throughput values could be compared with each other and the original system.

The simulation included several assumptions, which are listed here. These assumptions were necessary because of the limited data that could reasonably be obtained.

- All automated operation times were assumed to be constant, since the variation they exhibited was negligible.

- Since, under normal operating conditions, the cycle time of the first manual station (including any slight variability) is performed within the cycle time of the Pesmel system itself, it was ignored.

- Based on the limited data that could be collected for operator times at the second operator station, a triangular distribution was assumed with a minimum of $6 \mathrm{sec}$, a mode of $20 \mathrm{sec}$, and a maximum of $60 \mathrm{sec}$.

- Operators are always on-duty and available when needed. This is an operating policy that Pesmel would like to ensure is enforced.

- While some stations require a small mechanical reset time after a load transfer, that time was deemed inconsequential for equipment in which the reset is always completed before the next roll appears.

- The system is never starved or blocked (i.e., incoming rolls are always available and outgoing pallet loads are always removed).

- There are no frequent downtimes or interruptions to the processes that would significantly impact performance based on the solution proposed.

\section{VERIFICATION/VALIDATION}

Certain precautions were taken to ensure that the model would give valid throughput values which matched the actual system. One of these precautions was to include a 2-hour warm-up time that would not be included in the throughput calculation. This discounts the time at the beginning of a run during which the steady flow of rolls through the system is being established. Queue statistics and cycle times were tracked to ensure that the warm-up period was adequate.

One method used in debugging the model involved verifying an attribute's value by assigning a color to each value. It was then possible to visually monitor when an attribute was altered. Sensitivity analysis was also performed on equipment or stations where the exact cycle times were not known, such as with the proposed replacement conveyor or the first manual operation time, to show any effect on variations in the times.

The accuracy of the model was established by comparing the simulation to a video of the actual system. During certain periods of time in the video in which there were no downtimes or interruptions, the roll distribution was recorded as well as the operator times at the second operator station. These values were incorporated into the simulation and the resulting throughput was compared to the actual throughput of the system in the video. The values matched well, as shown in Table 1 below; the discrepancies found can be attributable to the lack of information on the first operator station (the operator times could not be detected from the video).

Table 1: Comparison of Steady-State Throughput

\begin{tabular}{|c|c|c|}
\hline Period & Video (Pallets/hour) & Simulation (Pallets/hour) \\
\hline 1 & 27 & 26.75 \\
\hline 2 & 18.6 & 19.125 \\
\hline 3 & 20 & 21.4 \\
\hline
\end{tabular}




\section{CONCEPT DESCRIPTIONS}

After brainstorming alternative solutions, several options were proposed for evaluation using simulation (see Figure 4).

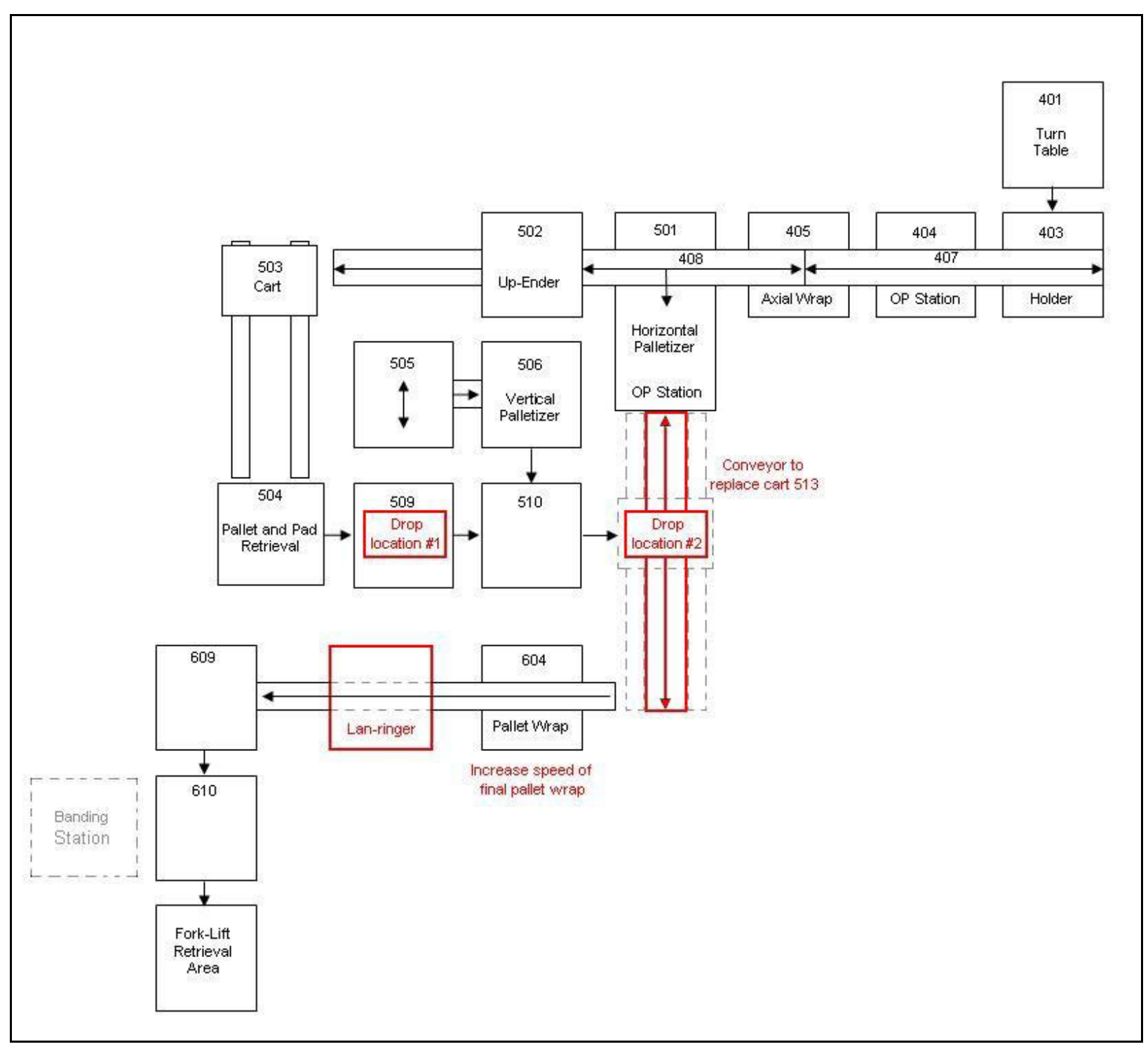

Figure 4: Simulation Screenshot of the Current Pesmel® System

A description of each of these options follows:

Triggering the pallets earlier. Pallet retrieval is triggered one station earlier (i.e., at the beginning of the first operator station as opposed to the beginning of the axial wrap station). Estimated cost: $\$ 5,000$.

Repaired/reprogrammed stretch wrapper. The cycle time of the final stretch wrapper is decreased from 125 seconds to 100 seconds. Estimated cost: \$25,000. 
Increased speed of Cart 513 by $40 \%$. Install a new motor and/or gearbox to reduce its cycle time by $40 \%$. Estimated Cost: $\$ 30,000$.

Replace Cart 513 with a conveyor. Cart 513 is replaced entirely by a two-way conveyor. The conveyor completes all the same tasks, but can handle more than one pallet when needed and requires no return time. Estimated cost: $\$ 110,000$.

Eliminate deck pads. Eliminate the use of a cardboard pad that is currently placed on every pallet as it enters the system. Estimated cost: none.

Two pallet-dispensing locations. Create a separate pallet delivery location for cradle packs and pancake stacks. Currently, all pallets are delivered at station 504 (as seen in Figure 3). Adding a separate drop location allows pallets to be delivered for cradle packs without having to wait for a pancake stack to finish. Estimated Cost $\$ 20,000$.

\section{CONCEPT TESTING AND RESULTS}

Several concepts and combinations of concepts were tested using the simulation. Some of these options and their resulting estimated throughputs are listed below. The variations in throughput are based on a $95 \%$ confidence interval with 10 replications.

1. Current system: $\mathbf{2 6 . 2} \pm \mathbf{0 . 3 1}$ pallets $/ \mathbf{h r}$

2. Triggering the pallet at the beginning of the first operator station (as opposed to the beginning of the axial wrap station): $\mathbf{2 6 . 2} \pm \mathbf{0 . 3 1}$ pallets/hr

3. Two dedicated operators, repaired/reprogrammed final stretch wrapper, increased speed of Cart 513 by $40 \%: \mathbf{3 1 . 9} \pm \mathbf{0 . 3 3}$ pallets $/ \mathbf{h r}$

4. Two dedicated operators, repaired/reprogrammed final stretch wrapper, Cart 513 replaced with a conveyor: $32.7 \pm \mathbf{0 . 6 5}$ pallets $/ \mathbf{h r}$

5. Two dedicated operators, repaired/reprogrammed final stretch wrapper, Cart 513 replaced with a conveyor, eliminated deck pad use: $33.7 \pm \mathbf{0 . 4 0}$ pallets $/ \mathbf{h r}$

6. Two dedicated operators, repaired/reprogrammed final stretch wrapper, Cart 513 replaced with a conveyor, eliminated deck pad use, two pallet dispensing/drop-off locations: $\mathbf{3 4 . 7} \pm \mathbf{0 . 3 8}$ pallets/hr

Through these simulations, it was possible to determine the statistical significance or insignificance in the increase of throughput for each of these combinations of concepts. It was found that the final combination in the above list resulted in the greatest increase in throughput with $34.7 \pm 0.38$ pallets $/ \mathrm{hr}$.

\section{CONCLUSION}

Based on the results of this simulation, four options were identified and proposed to Avery Dennison (numbers 3-6 in the above list of concept combinations). Each of these four combinations achieves the required $20 \%$ increase in throughput, ranging from a gain of $22 \%$ to $32 \%$ over the current system. Using simulation allowed each concept and combination to be tested quantitatively, not only permitting concepts to be ranked in relation to one another, but also giving management enough data to use in cost-benefit analyses. The management of Avery Dennison has reviewed the results of the simulation study and is now ready to make a decision based on the throughput and cost information provided.

\section{OBSERVATIONS}

Because of its complexity and variability, the Pesmel packaging system turned out to be an ideal candidate for simulation. Aside from actually implementing a concept and seeing how the system changes, there is not really any other way of quantifiably ranking concepts. Concepts can be sifted using qualitative factors, but judging a concept based on mere engineering intuition can promise results that are far from what would actually happen. For example, at the beginning of this project, many concepts were created 
and intuitively evaluated before the simulation was up and running. Many of the concepts that were chosen by the team as the most promising ended up making little difference when they were finally simulated. For example, when rolls enter the system, there is a delay before the pallet delivery system is triggered to bring a new pallet. Intuitively, it seemed that triggering the pallets earlier would easily fix a perceived bottleneck. However, when finally simulated, the gains from this concept were negligible even in combination with other concepts. Another benefit of using a simulation was the ease in which concepts could be combined in various ways to find the ideal combination. In this way, the synergistic effect of different combinations could be evaluated.

\section{REFERENCES}

Aybar, M., K. Potti, and T. LeBaron. 2002. Using Simulation to Understand Capacity Constraints and Improve Efficiency on Process Tools. In Proceedings of the 2002 Winter Simulation Conference, ed. E. Yücesan, C.-H. Chen, J. L. Snowdon, and J. M. Charnes, 1431-35. Piscataway, New Jersey: Institute of Electrical and Electronics Engineers, Inc.

Goldratt, E. M. 1993. The goal. New York: NAL/Dutton.

Harrell, C., B. Ghosh, and R. Bowden. 2004. Simulation Using ProModel, $2^{\text {nd }}$ ed., New York: McGrawHill.

Phillips, D. T. 1983. Simulation of Material Handling Systems: Perspectives and Possibilities. Journal of Industrial Engineering, September issue, 65-77.

Rippenhagen, C., and S. Krishnaswamy. 1998. Implementing the Theory of Constraints Philosophy in Highly Reentrant Systems. Proceedings of the 1998 Winter Simulation Conference, ed. D.J. Medeiros, E.F. Watson, J.S. Carson and M.S. Manivannan. 993-96. Piscataway, New Jersey: Institute of Electrical and Electronics Engineers, Inc.

Zottolo, M., K. Vasudevan, S. Soni, and E. Williams. 2009. Simulation \& Theory of Constraints: Developing a Throughput Improvement Roadmap for an Engine Core Block Manufacturing Facility. Case study presentation at 2009 Winter Simulation Conference, 13-16 December 2009 Hilton Austin Hotel, Austin, TX.

\section{AUTHOR BIOGRAPHIES}

CHARLES HARRELL is an Associate Professor in the college of Engineering and Technology at Brigham Young University and is the founder of ProModel Corporation. His area of expertise is in the simulation of manufacturing and supply-chain systems with emphasis on the application of lean concepts and practices. At BYU he teaches courses in manufacturing systems, manufacturing simulation, and manufacturing information systems. He is the principal author of several simulation books and has given numerous presentations on manufacturing system design and simulation. He serves on the board of directors of ProModel Corp. and on the Simulation Standards Committee convened by the National Institute of Standards and Technology (NIST). He also leads the enterprise modeling technical subgroup for SME. He is a senior member of IIE and SME. His email address is <harrellc@byu.edu>.

SETH WINSOR is a graduate of the Mechanical Engineering program at Brigham Young University. His email address is $<7$ winsor@gmail.com $>$.

GREG TEICHERT is a senior in Mechanical Engineering at Brigham Young University. His email address is $<$ gregteichertegmail.com>. 